\title{
An Unusual Case of Wart-like Presentation of Ocular Surface Squamous Neoplasia
}

\author{
Nirsara Shrestha ${ }^{1}$, Sangeeta Shrestha ${ }^{1}$, Arjun Shrestha ${ }^{1}$ \\ ${ }^{1}$ Department of Ophthalmology, Children's Hospital For Eye Ear and Rehabilitation Service (CHEERS), Bhaktapur, Nepal
}

\section{ABSTRACT}

\begin{abstract}
The ocular surface squamous neoplasia refers to the entire spectrum ranging from mild to severe dysplasia to carcinoma in situ and invasive squamous cell carcinoma. Ocular surface squamous neoplasia may present clinically in various ways: gelatinous, velvety or papilliform or leukoplakic. This case report describes a 50-year-old male who presented with a filiform wart-like appearance of conjunctival mass unlike described earlier. Excisional biopsy was done and histopathology revealed intraepithelial neoplasia with high-grade dysplasia.
\end{abstract}

Keywords: Dysplasia; Intraepithelial neoplasm; Ophthalmology; OSSN

\author{
Correspondence: \\ Dr. Nirsara Shrestha, MD \\ Ophthalmologist, Department of Ophthalmology, \\ Children's Hospital For Eye Ear and Rehabilitation \\ Service (CHEERS), Bhaktapur, Nepal. \\ ORCID ID: 0000-0001-6052-1201 \\ Email: nirsara.shrestha@gmail.com
}

Submitted $: 25^{\text {th }}$ September 2019 Accepted : $16^{\text {th }}$ December 2019

Source of Support: None

Conflict of Interest: No

Citation: Shrestha N, Shrestha A. An unusual case of wart-like presentation of ocular surface squamous neoplasia. NMJ 2019;2 (2): 270-1. DOI 10.3126/ nmj.v2i2.26965

\section{INTRODUCTION}

The ocular surface squamous neoplasia (OSSN) refers to the entire spectrum of conditions ranging from dysplasia to carcinoma in situ and invasive squamous cell carcinoma. These ocular surface lesions were termed as OSSN by Lee and Hirst. ${ }^{1}$ The known risk factors for the development of OSSN are advanced age, male gender, and exposure to solar ultraviolet radiation, infection with human papillomavirus (HPV), immunosuppression and infection with human immunodeficiency virus (HIV). ${ }^{2}$ OSSN can present in various ways: gelatinous, velvety, papilliform or leukoplakic. The most common one among these three is the gelatinous lesion with characteristic tufted superficial vessels. ${ }^{3}$ These lesions are located mostly at the limbus and interpalpebral fissure. It may also spread to the cornea as an opaque, frosted membranous like tissue with fabricated borders covering the corneal periphery. ${ }^{4}$ The first case of OSSN was described by von Graefe in $1860 .{ }^{5}$ Many cases have been reported and researches been done in this field leading to significant improvement in the diagnosis and treatment of the disease. Here we report a case of OSSN which has an unusual wart-like presentation instead of a conventional one.

\section{\# CASE REPORT}

A 50-years-male presented with complaint of painless swelling in the nasal bulbar conjunctiva of his left eye. He first noticed the mass three months prior to presentation. He gave a history of redness of the left eye, not associated with discharge or bleeding. Shortly thereafter, he noticed a wart-like projection from the mass which was progressive in size and pigmented in nature. There 
was no history of trauma or any ocular surgery in the past. The patient did not have any systemic or cutaneous abnormalities.

The ocular examination showed visual acuity of $6 / 6$ in both the eyes. The intraocular pressure was $14 \mathrm{~mm}$ of $\mathrm{Hg}$ with Goldmann applanation tonometer in bilaterally. The extraocular movements were full in all positions. The lids were normal. The conjunctiva of the left eye was diffusely congested and had a fragile mass on the bulbar conjunctiva involving $2.0 \mathrm{~mm}$ of the nasal cornea at 9 o'clock which did not bleed in touch. The mass was $5 \mathrm{~mm}$ x $4 \mathrm{~mm}$ in size and had a filiform wart-like appearance with superficial feeding vessels in the temporal part and gelatinous in the nasal part. It was mobile and did not invade the underlying sclera (fig 1). The rest of the anterior and posterior segments of both eyes were normal.

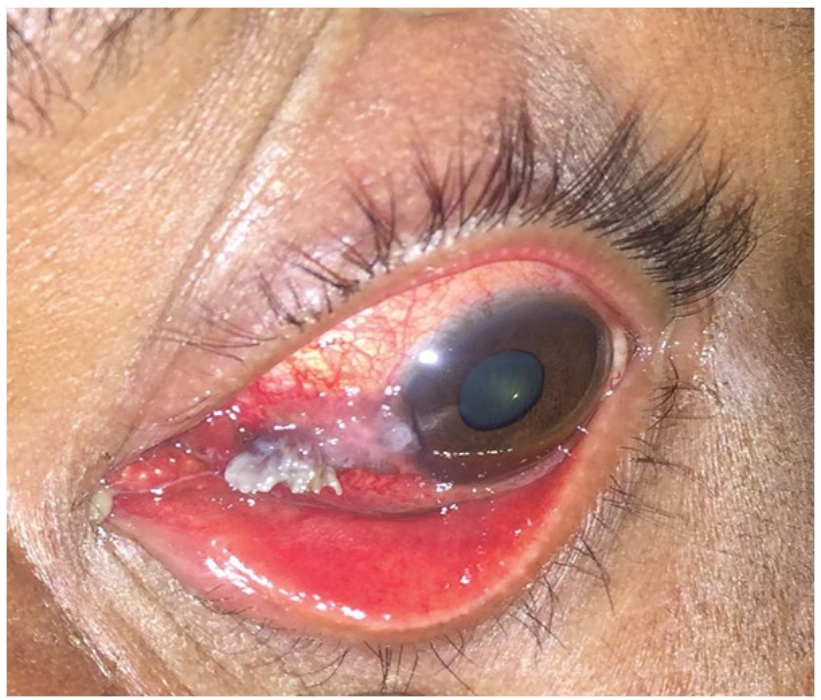

Figure 1: Photograph showing a filiform variant of conjunctival mass in the nasal area with leukoplakic changes encroaching towards the cornea

With a differential diagnosis of a HPV associated lesion, pseudoepitheliomatous hyperplasia and actinic disease; excisional biopsy of the lesion, was planned. Also taking the probability of OSSN into consideration, with a non-touch technique, excision of the mass was done under local anesthesia. The mass was sent for histopathological examination which showed intraepithelial neoplasia with high-grade dysplasia (fig. 2). The margins were free of tumor. The patient did not show any signs of recurrence at six months follow up.

\section{REFERENCES}

1. Lee GA, Hirst LW. Ocular surface squamous neoplasia. Surv Ophthalmol. 1995;39(6):429-50. $\underline{\text { Crossref }}$

2. Mittal R, Rath S, Vemuganti GK. Ocular surface squamous neoplasia - Review of etiopathogenesis and an update on clinico-pathological diagnosis. Saudi J Ophthalmol 2013;27(3):177-86. Crossref

3. Pizzarello LD, Jakobiec FA. Bowen's disease of the conjunctiva: a misnomer. In: Jakobiec FA, eds. Ocular and Adnexal Tumors. ed. Birmingham, AL: Aesculapius; 1978. p553-71.

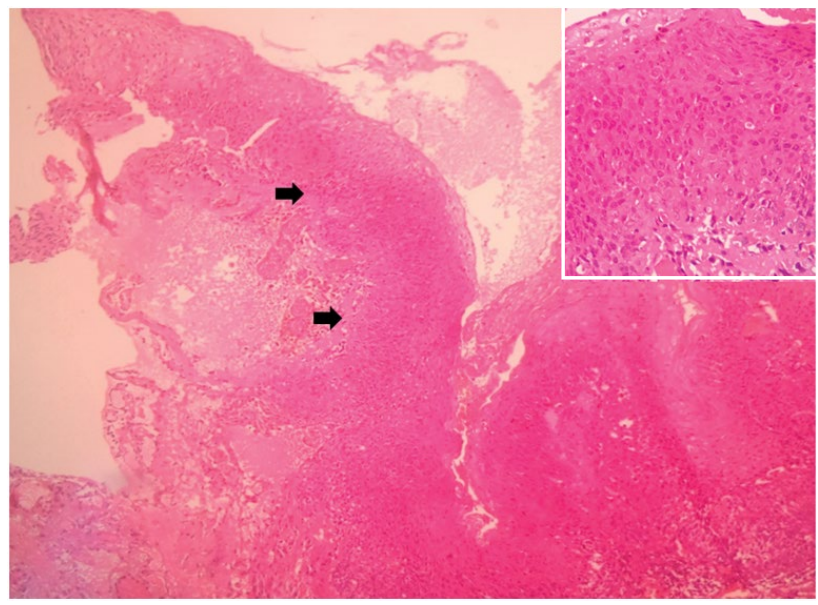

Figure 2: Photomicrograph showing tissue lined by stratified squamous epithelium with the focal area with dysplastic epithelium involving almost entire thickness. Maturation is maintained. (HE stain; X100) Inset showing loss of polarity and abnormal mitosis. (HE stain; X400)

\section{DISCUSSION}

OSSN is the third most common ocular tumor after melanoma and lymphoma and is known to have a varied presentation. Due to the variation in the presentation, some of them may go unnoticed whereas some may be misdiagnosed clinically due to a bizarre presentation instead of the conventional gelatinous, papillomatous and leukoplakic appearance. ${ }^{6}$ The presentation of OSSN in our case is a rare one which, to our knowledge, has not been reported so far. The patient gave the usual history of OSSN but the clinical picture was misleading. At a glance, it appeared similar to a skin wart caused by HPV that is rarely seen in the conjunctiva.

OSSN may not have a typical presentation at all times. Any unusual appearance of the ocular surface should be evaluated in detail to exclude OSSN. In the early stage, it is usually curative after treatment but advanced cases can lead to mutilating surgery like enucleation and exenteration. In order to prevent this, early detection is essential which is possible if the examiner is aware of the varied presentation of OSSN and hence OSSN should be included in the differential diagnosis of every case of conjunctival mass with a supporting risk factor or history which points toward OSSN.

4. Nelson KD, McSoley JJ. Clinical findings and management of conjunctival intraepithelial neoplasia. Optometry 2011;82(1):15-21. Crossref

5. Duke-Elder S, Leigh AG. Diseases of the outer eye. In: Duke-Elder S, ed. Systems of Ophthalmology. Vol.7. ed. St Louis: CV Mosby; 1985. p1154-59.

6. Basti S, Mascai MS. Ocular surface squamous neoplasia: a review. Cornea 2003; 22(7):687-704. Crossref 